Article

\title{
Performance Assessment of SARS-CoV-2 PCR Assays Developed by WHO Referral Laboratories
}

\author{
Sibyle Etievant ${ }^{1,2, *, \dagger}{ }^{\dagger}$ Antonin Bal ${ }^{1,2,3,4,{ }^{\dagger}}$, Vanessa Escuret ${ }^{1,2,4}{ }^{\oplus}$, Karen Brengel-Pesce ${ }^{3}$, \\ Maude Bouscambert ${ }^{1,2} \oplus$, Valérie Cheynet ${ }^{3}$, Laurence Generenaz ${ }^{3}$, Guy Oriol ${ }^{3}$, \\ Gregory Destras ${ }^{1}$, Geneviève Billaud ${ }^{1}$, Laurence Josset ${ }^{1,4}{ }^{(D}$, Emilie Frobert ${ }^{1,4}$, \\ Florence Morfin ${ }^{1,4}$ and Alexandre Gaymard 1,2,4,*(D) \\ 1 Laboratoire de Virologie, Institut des Agents Infectieux (IAI), Hospices Civils de Lyon, Groupement \\ Hospitalier Nord, 69004 Lyon, France; antonin.bal@chu-lyon.fr (A.B.); vanessa.escuret@chu-lyon.fr (V.E.); \\ maude.bouscambert-duchamp@chu-lyon.fr (M.B.); gregory.destras@chu-lyon.fr (G.D.); \\ genevieve.billaud@chu-lyon.fr (G.B.); laurence.josset@chu-lyon.fr (L.J.); emilie.frobert@chu-lyon.fr (E.F.); \\ florence.morfin-sherpa@chu-lyon.fr (F.M.) \\ 2 Centre National de Référence des Virus Respiratoires, Hospices Civils de Lyon, Groupement Hospitalier \\ Nord, 69004 Lyon, France \\ 3 Laboratoire Commun de Recherche Hospices Civils de Lyon-bioMérieux, Centre Hospitalier Lyon Sud, \\ 69310 Pierre-Bénite, France; Karen.BRENGEL-PESCE@biomerieux.com (K.B.-P.); \\ Valerie.CHEYNET@biomerieux.com (V.C.); laurence.generenaz@biomerieux.com (L.G.); \\ Guy.ORIOL@biomerieux.com (G.O.) \\ 4 Université de Lyon, Virpath, CIRI, INSERM U1111, CNRS UMR5308, ENS Lyon, Université Claude Bernard \\ Lyon 1, F-69372 Lyon, France \\ * Correspondence: sibyle.etievant@chu-lyon.fr (S.E.); alexandre.gaymard@chu-lyon.fr (A.G.); \\ Tel.: +33-(0)4-72-07-11-11 (S.E.); +33-(0)4-72-07-10-53 (A.G.) \\ + Equal contributions.
}

Received: 24 April 2020; Accepted: 11 June 2020; Published: 16 June 2020

\begin{abstract}
A reliable diagnostic assay is crucial to early detect new COVID-19 cases and limit severe acute respiratory syndrome coronavirus 2 (SARS-CoV-2) transmission. Since the onset of the COVID-19 pandemic, the World Health Organization has published several diagnostic molecular approaches developed by referral laboratories, including Charité (Germany), HKU (Hong Kong), China CDC (China), US CDC (United States), and Institut Pasteur, Paris (France). We aimed to compare the sensitivity and specificity of these different RT-PCR assays using SARS-CoV-2 cell culture supernatants and clinical respiratory samples. Overall, the different RT-PCR assays performed well for SARS-CoV-2 detection and were all specific except the N Charite (Germany), and N2 US CDC (United States) assays. RdRp Institut Pasteur (IP2, IP4), N China CDC, and N1 US CDC were found to be the most sensitive assays. The data presented herein are of prime importance to facilitate the equipment choice of diagnostic laboratories, as well as for the development of marketed tests.
\end{abstract}

Keywords: SARS-CoV-2; COVID-19; RT-PCR; diagnostics; sensitivity

\section{Introduction}

A new human coronavirus called severe acute respiratory syndrome coronavirus 2 (SARS-CoV-2) emerged in China in December 2019 [1]. SARS-CoV-2 is responsible for coronavirus disease 2019 (COVID-19), which was declared a pandemic on 12 March 2020 by the World Health Organization (WHO) [2]. As of 26 May 2020, 5,404,512 cases have been reported, including 343,514 deaths [3]. A reliable diagnostic assay is crucial to limit the spread of SARS-CoV-2 as early detection of new cases leads to patient isolation and contact tracing. The first SARS-CoV-2 genome was published on 
10 January 2020 [4], enabling the rapid design of a real-time reverse-transcriptase polymerase chain reaction (RT-PCR) assay by Charite (Germany) [5,6]. This test was the first to be dispatched by WHO [7] and was widely implemented in clinical virology laboratories worldwide [8]. Since then, WHO has published [9] other approaches developed by referral laboratories, including HKU (Hong Kong) [10,11], China CDC (China) [12], US CDC (United States) [13], and Institut Pasteur, Paris (France) [14]. These assays included several RT-PCRs targeting two or three different SARS-CoV-2 gene regions, including RdRp (RNA-dependent RNA polymerase), N (nucleocapsid protein), E (envelope protein), ORF1ab nsp10 (non-structural protein 10), and ORF1b nsp14 (non-structural protein 14). In the present study, we aimed to compare the sensitivity and specificity of these different RT-PCR assays. Overall, the different RT-PCR assays performed well for SARS-CoV-2 detection and were all specific except N Charité, (Germany) and N2 US CDC (United States) assays. RdRp Institut Pasteur (IP2, IP4), N China CDC, and N1 US CDC were found to be the most sensitive assays.

\section{Materials and Methods}

\subsection{Study Design}

To assess sensitivity, different RNA concentrations of SARS-CoV-2 cell culture supernatants, as well as clinical samples with different viral loads $(n=4)$, were tested using all RT-PCR assays. For the three most sensitive assays, limit of detection (LoD) was assessed, and additional clinical samples $(n=16)$ with low viral loads were also tested. To assess specificity, clinical samples negative for SARS-CoV-2 $(n=50)$ were tested using all RT-PCR assays. All clinical samples (nasopharyngeal aspirates) were provided by the Hospices Civils de Lyon-University Hospital, France, and frozen at $80^{\circ} \mathrm{C}$ before extraction.

\subsection{Sensitivity}

The sensitivity for each RT-PCR assay was first assessed using ten-fold serial dilutions from $10^{-3}$ to $10^{-9}$ of SARS-CoV-2 cell culture supernatants (one replicate for $10^{-3}$ and $10^{-4}$, three replicates for $10^{-5}$ and $10^{-6}$, and five replicates for $10^{-7}$ to $10^{-9}$ ). Four positive clinical samples were then tested using all RT-PCR assays to confirm these results.

For the three most sensitive assays, we estimated the LoD using a probit analysis by including five additional replicates of each dilution of the cell culture supernatants. Probit analysis consists of describing the relationship between the probability of detection and concentration using a cumulative probability curve. For each dilution, the ratio (the hit rate) is computed as the number of replicates with a detected outcome per the total number of replicates tested. These hit rates are converted mathematically into cumulative normal probability units (probits) and fitted using a regression model vs. their respective concentrations. The $\mathrm{LoD}$ is defined as the lowest amount of viral genome that can be detected with a $95 \%$ hit rate. For these three most sensitive assays, the results obtained with probit analysis were confirmed by additional testing of sixteen clinical samples with low viral concentration.

\subsection{Specificity}

The specificity for each RT-PCR assay was assessed using clinical samples $(n=50)$ tested negative for SARS-CoV-2, including clinical samples $(n=30)$ tested positive for other respiratory viruses: human coronaviruses 229E, OC43, HKU1, and NL63, human influenza A and B viruses, rhinovirus, respiratory syncytial virus, parainfluenzavirus, adenovirus, metapneumovirus, and picornavirus.

Exploration of false-positive results was performed with additional negative clinical samples, water, and one additional clinical sample tested positive for each target. Amplicon size was analyzed using Agilent DNA 1000 kit (Agilent Technologies, Santa Clara, CA, USA). 


\subsection{SARS-CoV-2 Cell Culture Supernatants}

Cell culture supernatants were obtained from a positive clinical sample cultivated in a biosafety level 3 laboratory on buffalo green monkey cells (cell line provided by the Université Louis Pasteur, Strasbourg, France) [15]. The SARS-CoV-2 culture had an infectious titer of $8.27 \log _{10} \mathrm{TCID}_{50} / \mathrm{mL}$ as assessed by the Reed and Muench statistical method [16].

\subsection{Extraction and RT-PCR}

RNA extraction was performed using the EMAG ${ }^{\circledR}$ platform (bioMérieux, Marcy-l'Étoile, France), according to manufacturer's instructions. RT-PCR was performed following published instructions [5,6,10-14], which are summarized in Table 1; Table 2. Since the China CDC protocol does not specify polymerase, thermocycler, volume of nucleic acid extract, and amplification cycles, the same instructions as those for the HKU assay were applied. RdRp IP2 and IP4 assays from Institut Pasteur, Paris (France) can be multiplexed or used in simplex [14]. Preliminary comparison on SARS-CoV-2 cell culture supernatants found that RdRp IP4 performed better when used in multiplex, whereas IP2 was not significantly impacted (Supplementary Table S1). The CFX 96 Touch $^{\mathrm{TM}}$ Real-Time PCR (Bio-Rad, Hercules, CA, USA) was used for all RT-PCR assays. 
Table 1. Summary of the five RT-PCR assays targeting severe acute respiratory syndrome coronavirus 2 (SARS-CoV-2).

\begin{tabular}{|c|c|c|c|c|c|c|c|}
\hline $\begin{array}{l}\text { Country } \\
\text { (Institute) }\end{array}$ & Target & Oligonucleotide & Sequence & $\begin{array}{c}\text { Amplicon } \\
\text { Size }^{\mathrm{a}}\end{array}$ & Polymerase & $\begin{array}{l}\text { Thermocycler Used in the } \\
\text { Reference Publication }\end{array}$ & $\begin{array}{c}\text { Volume of } \\
\text { RNA Extract }\end{array}$ \\
\hline \multirow{10}{*}{$\begin{array}{c}\text { Charité } \\
\text { (Germany) [5,6] }\end{array}$} & \multirow{4}{*}{$\operatorname{RdRp}^{\mathrm{b}}$} & Charité_RdRp_F & GTGARATGGTCATGTGTGGCGG & \multirow{4}{*}{$100 \mathrm{bp}$} & \multirow{10}{*}{$\begin{array}{c}\text { SuperScript }{ }^{\mathrm{TM}} \text { III } \\
\text { Platinum }{ }^{\circledR} \text { One-Step } \\
\text { Quantitative RT-PCR } \\
\text { System }\end{array}$} & \multirow{10}{*}{$\begin{array}{l}\text { Light Cycler }{ }^{\circledR} 480 I I \\
\text { (Roche) or Applied } \\
\text { Biosystems ViiA } \\
\text { (Therom Fisher) }\end{array}$} & \multirow{10}{*}{$5 \mu \mathrm{L}$} \\
\hline & & Charité_S_RdRp_P ${ }^{c}$ & FAM-CAGGTGGAACCTCATCAGGAGATGC-BBQ & & & & \\
\hline & & Charité_NS_RdRp_Pd & FAM-CCAGGTGGWACRTCATCMGGTGATGC-BBQ & & & & \\
\hline & & Charité_RdRp_R & CARATGTTAAASACACTATTAGCATA & & & & \\
\hline & \multirow{3}{*}{$\mathrm{E}^{\mathrm{e}}$} & Charité_E_F & ACAGGTACGTTAATAGTTAATAGCGT & \multirow{3}{*}{$113 \mathrm{bp}$} & & & \\
\hline & & Charité_E_P & FAM-ACACTAGCCATCCTTACTGCGCTTCG-BBQ & & & & \\
\hline & & Charité_E_R & ATATTGCAGCAGTACGCACACA & & & & \\
\hline & \multirow{3}{*}{$\mathrm{N}$} & Charité_N_F & CACATTGGCACCCGCAATC & \multirow{3}{*}{$128 \mathrm{bp}$} & & & \\
\hline & & Charité_N_P & FAM-ACTTCCTCAAGGAACAACATTGCCA-BBQ & & & & \\
\hline & & Charité_N_R & GAGGAACGAGAAGAGGCTTG & & & & \\
\hline \multirow{6}{*}{$\begin{array}{l}\text { HKU (Hong } \\
\text { Kong) [10,11] }\end{array}$} & \multirow{4}{*}{ ORF1b-nsp $14^{\mathrm{f}}$} & HKU_ORF_F & TGGGGYTTTACRGGTAACCT & \multirow{3}{*}{$132 \mathrm{bp}$} & \multirow{6}{*}{$\begin{array}{l}\text { TaqMan Fast Virus } \\
\text { Master mix }\end{array}$} & \multirow{6}{*}{$\begin{array}{l}\text { Applied Biosystems } \\
\text { ViiA }^{\mathrm{TM}} \text { (Therom Fisher) }\end{array}$} & \multirow{6}{*}{$4 \mu \mathrm{L}$} \\
\hline & & HKU_ORF_P & FAM-TAGTTGTGATGCWATCATGACTAG-TAMRA & & & & \\
\hline & & HKU_ORF_R & AACRCGCTTAACAAAGCACTC & & & & \\
\hline & & HKU_N_F & TAATCAGACAAGGAACTGATTA & \multirow{3}{*}{$110 \mathrm{bp}$} & & & \\
\hline & \multirow[t]{2}{*}{$\mathrm{N}^{\mathrm{e}}$} & HKU_N_P & FAM-GCAAATTGTGCAATTTGCGG-TAMRA & & & & \\
\hline & & HKU_N_R & CGAAGGTGTGACTTCCATG & & & & \\
\hline \multirow{6}{*}{$\begin{array}{l}\text { China CDC } \\
\text { (China) [12] }\end{array}$} & \multirow{3}{*}{$\mathrm{N}$} & ChinaCDC_N_F & GGGGAACTTCTCCTGCTAGAAT & \multirow{3}{*}{$99 \mathrm{bp}$} & \multirow{6}{*}{ Unspecified } & \multirow{6}{*}{ Unspecified } & \multirow{6}{*}{ Unspecified } \\
\hline & & ChinaCDC_N_P & FAM-TTGCTGCTGCTTGACAGATT-TAMRA & & & & \\
\hline & & ChinaCDC_N_R & CAGACATTTTGCTCTCAAGCTG & & & & \\
\hline & \multirow{3}{*}{ ORF1ab-nsp10 } & ChinaCDC_ORF_F & CCCTGTGGGTTTTACACTTAA & \multirow{3}{*}{$119 \mathrm{bp}$} & & & \\
\hline & & ChinaCDC_ORF_P & FAM-CCGTCTGCGGTATGTGGAAAGGTTATGG-BHQ1 & & & & \\
\hline & & ChinaCDC_ORF_R & ACGATTGTGCATCAGCTGA & & & & \\
\hline \multirow{9}{*}{$\begin{array}{c}\text { US CDC } \\
\text { (United States) [13] }\end{array}$} & \multirow{3}{*}{$\mathrm{N} 1^{\mathrm{c}}$} & USCDC_N1_F & GACCCCAAAATCAGCGAAAT & \multirow{3}{*}{$72 \mathrm{bp}$} & & & \\
\hline & & USCDC_N1_P & FAM-ACCCCGCATTACGTTTGGTGGACC-BHQ1 & & & & \\
\hline & & USCDC_N1_R & TCTGGTTACTGCCAGTTGAATCTG & & & & \\
\hline & & USCDC_N2_F & TTACAAACATTGGCCGCAAA & & & & \\
\hline & $\mathrm{N} 2^{\mathrm{c}}$ & USCDC_N2_P & FAM-ACAATTTGCCCCCAGCGCTTCAG-BHQ1 & $67 \mathrm{bp}$ & RT-qPCR Master Mix, & $\begin{array}{l}\text { Applied Biosystems' }{ }^{\text {TM }} 7500 \\
\text { Fast (Thermo Fisher) }\end{array}$ & $5 \mu \mathrm{L}$ \\
\hline & & USCDC_N2_R & GCGCGACATTCCGAAGAA & & & & \\
\hline & & USCDC_N3_F & GGGAGCCTTGAATACACCAAAA & & & & \\
\hline & $\mathrm{N}^{\mathrm{d}}$ & USCDC_N3_P & FAM-AYCACATTGGCACCCGCAATCCTG-BHQ1 & $72 \mathrm{bp}$ & & & \\
\hline & & USCDC_N3_R & TGTAGCACGATTGCAGCATTG & & & & \\
\hline
\end{tabular}


Table 1. Cont.

\begin{tabular}{|c|c|c|c|c|c|c|c|}
\hline $\begin{array}{c}\text { Country } \\
\text { (Institute) }\end{array}$ & Target & Oligonucleotide & Sequence & $\begin{array}{c}\text { Amplicon } \\
\text { Size }^{\mathrm{a}}\end{array}$ & Polymerase & $\begin{array}{l}\text { Thermocycler Used in the } \\
\text { Reference Publication }\end{array}$ & $\begin{array}{c}\text { Volume of } \\
\text { RNA Extract }\end{array}$ \\
\hline \multirow{6}{*}{$\begin{array}{l}\text { Institut Pasteur, } \\
\text { Paris (France) [14] }\end{array}$} & \multirow{3}{*}{ RdRp IP2 (Flo2) } & Pasteur_IP2_F & ATGAGCTTAGTCCTGTTG & \multirow{3}{*}{$108 \mathrm{bp}$} & \multirow{6}{*}{$\begin{array}{c}\text { SuperScript }{ }^{\mathrm{TM}} \text { III } \\
\text { Platinum }{ }^{\circledR} \text { One-Step } \\
\text { Quantitative RT-PCR } \\
\text { System }\end{array}$} & \multirow{6}{*}{ LightCycler ${ }^{\circledR} 480$ (Roche) } & \multirow{6}{*}{$5 \mu \mathrm{L}$} \\
\hline & & Pasteur_IP2_P & HEX-AGATGTCTTGTGCTGCCGGTA-BHQ1 & & & & \\
\hline & & Pasteur_IP2_R & CTCCCTTTGTTGTGTTGT & & & & \\
\hline & \multirow{3}{*}{ RdRp IP4 (Flo4) } & Pasteur_IP4_F & GGTAACTGGTATGATTTCG & \multirow{3}{*}{$107 \mathrm{bp}$} & & & \\
\hline & & Pasteur_IP4_P & FAM-TCATACAAACCACGCCAGG-BHQ1 & & & & \\
\hline & & Pasteur_IP4_R & CTGGTCAAGGTTAATATAGG & & & & \\
\hline
\end{tabular}

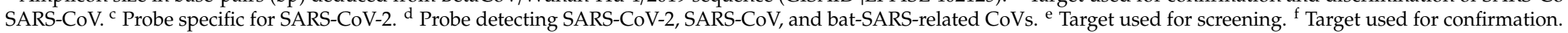

Table 2. Amplification cycles of the five RT-PCR assays targeting SARS-CoV-2.

\begin{tabular}{|c|c|c|c|c|c|c|c|c|c|c|c|c|c|c|c|}
\hline \multirow{2}{*}{$\begin{array}{c}\text { Institute (Country) } \\
\text { Amplification Cycles }\end{array}$} & \multicolumn{3}{|c|}{ Charité (Germany) $[5,6]$} & \multicolumn{3}{|c|}{ HKU (Hong Kong) [10,11] } & \multicolumn{3}{|c|}{ China CDC (China) [12] } & \multicolumn{3}{|c|}{ US CDC (United States) [13] } & \multicolumn{3}{|c|}{ Institut Pasteur, Paris (France) } \\
\hline & $\mathrm{T}^{\circ} \mathrm{C}$ & $\begin{array}{l}\text { Time } \\
\text { (min) }\end{array}$ & $\begin{array}{l}\text { Number } \\
\text { of Cycles }\end{array}$ & $\mathrm{T}^{\circ} \mathrm{C}$ & $\begin{array}{l}\text { Time } \\
\text { (min) }\end{array}$ & $\begin{array}{l}\text { Number } \\
\text { of Cycles }\end{array}$ & $\mathrm{T}^{\circ} \mathrm{C}$ & $\begin{array}{l}\text { Time } \\
\text { (min) }\end{array}$ & $\begin{array}{c}\text { Number } \\
\text { of Cycles }\end{array}$ & $\mathrm{T}^{\circ} \mathrm{C}$ & $\begin{array}{l}\text { Time } \\
\text { (min) }\end{array}$ & $\begin{array}{c}\text { Number } \\
\text { of Cycles }\end{array}$ & $\mathrm{T}^{\circ} \mathrm{C}$ & $\begin{array}{l}\text { Time } \\
\text { (min) }\end{array}$ & $\begin{array}{c}\text { Number of } \\
\text { Cycles }\end{array}$ \\
\hline Uracil-N-glycosylase activation & & & & & & & & \multirow{6}{*}{\multicolumn{2}{|c|}{ Unspecified }} & 25 & 02:00 & & & & \\
\hline Reverse transcription & 55 & 10:00 & & 50 & 05:00 & & & & & 50 & 15:00 & 1 & 55 & 20:00 & 1 \\
\hline RT inactivation/Enzyme activation & 95 & 03:00 & 1 & 95 & $00: 20$ & 1 & & & & 95 & 02:00 & & 95 & 03:00 & 1 \\
\hline Denaturation & 95 & $00: 15$ & & 95 & 00:05 & & & & & 95 & $00: 03$ & & 95 & $00: 15$ & \\
\hline Annealing/Extending & 58 & $00: 30$ & 45 & 60 & $00: 30$ & 40 & & & & 55 & $00: 30$ & 45 & 58 & $00: 30$ & 50 \\
\hline Cooling & & & & & & & & & & & & & 40 & $00: 30$ & 1 \\
\hline
\end{tabular}




\section{Results}

\subsection{Sensitivity Comparison of the Five RT-PCR Assays}

The E Charité and N2 US CDC assays were positive for all specimens, including negative samples and negative controls (water). These false-positive results were explored (details below), but the sensitivity of these assays was not further assessed.

Sensitivity was first assessed using SARS-CoV-2 cell culture supernatants. Using both specific SARS-CoV-2 (S) and non-specific (NS; detecting SARS-CoV-2, SARS-CoV, and bat-SARS-related CoVs) $\operatorname{RdRp}$ Charite assays, all replicates of the $10^{-5}$ dilution (and inferior); $1 / 3$ (S RdRp) and 3/3 (NS RdRp) of the $10^{-6}$ dilution replicates; and none of the $10^{-7}, 10^{-8}$, and $10^{-9}$ dilutions $(0 / 5)$ were detected. ORF1b and N HKU, and ORF1ab China CDC assays detected all replicates of dilutions inferior or equal to $10^{-6}$ and detected $4 / 5,3 / 5$, and $2 / 5$ for $10^{-7}$ dilutions, respectively. None of these assays detected replicates of $10^{-8}(0 / 5)$ and $10^{-9}(0 / 5)$ dilutions. In contrast, N Charité, N China CDC, N1 and N3 US CDC, and duplex RdRp IP2/IP4 were positive for most replicates of the $10^{-7}(5 / 5,5 / 5,5 / 5,4 / 5,5 / 5$ and $5 / 5$, respectively) and $10^{-8}$ dilutions $(3 / 5,2 / 5,4 / 5,5 / 5,3 / 5,3 / 5$, respectively; Figure 1$)$. At $10^{-9}$ dilution, N China, N1 and N3 US CDC, and duplex RdRp IP2/IP4 assays were able to detect replicates $(1 / 5,1 / 5$, $2 / 5,3 / 5,1 / 5$, respectively).

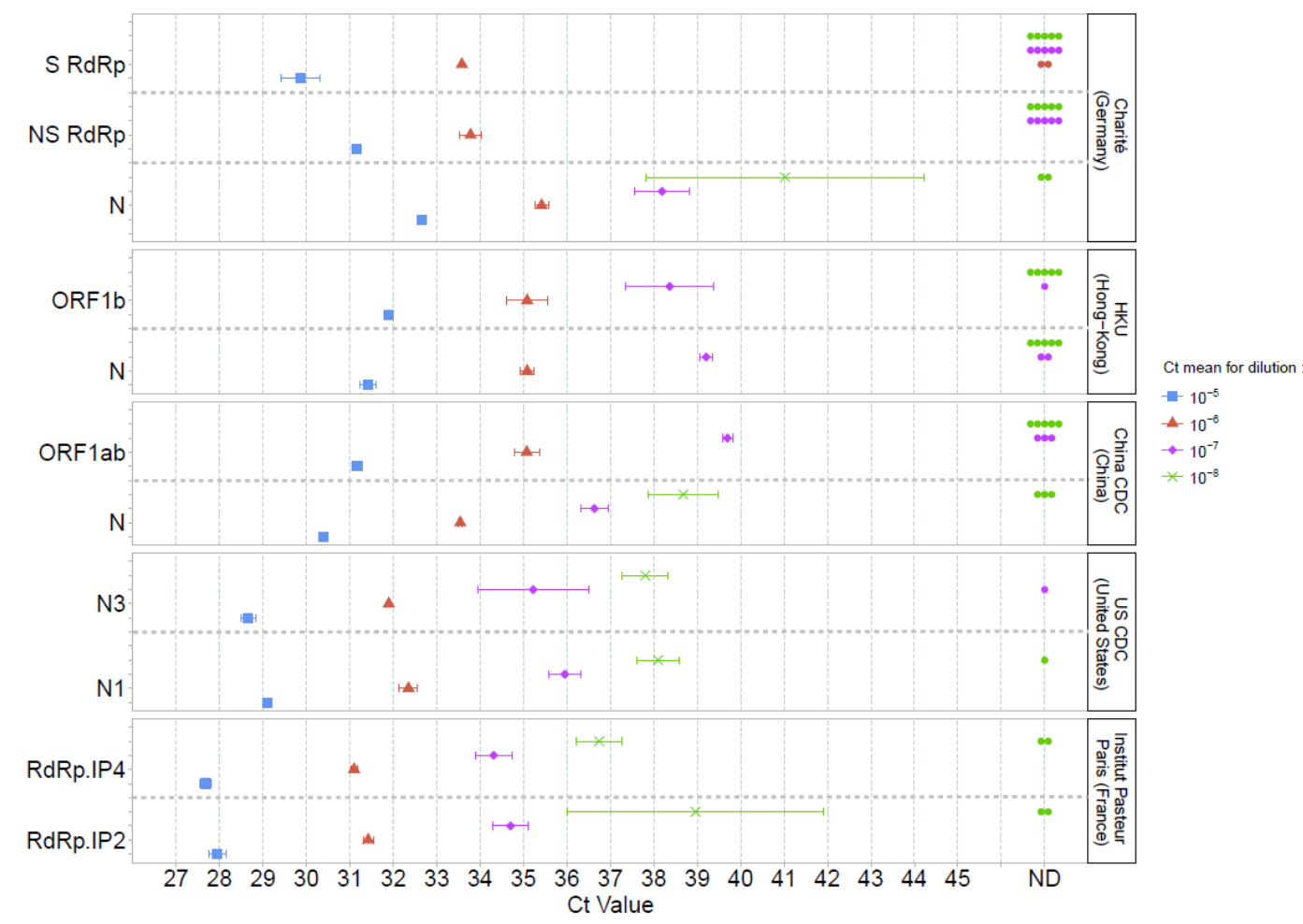

Figure 1. Mean Ct values and standard deviations obtained using five PCR-based methods for SARS-CoV-2 detection. Serial dilutions of SARS-CoV-2 cell culture supernatants were used and are represented by a single color $\left(10^{-5}\right.$ blue, $10^{-6}$ red, $10^{-7}$ pink, $10^{-8}$ green). A point in the ND (non-detected) column (Ct value axis) indicates a negative result for one replicate.

The mean cycle threshold $(\mathrm{Ct})$ values obtained for each assay were then compared for dilutions $10^{-5}$ to $10^{-8}$ (Figure 1, Supplementary Table S2). Since the accepted technical variability of RT-PCR is below $0.5 \log _{10}$, we considered a difference of $2 \mathrm{Ct}$ as significant [17]. At $10^{-5}$ dilution, the lowest $\mathrm{Ct}$ value was 27.7 for RdRp IP4. No significant difference in Ct values (Ct ranged from 28.0 to 29.1) was reported with N1 and N3 US CDC, and RdRp IP2. A similar Ct profile was observed for these assays at $10^{-6}$ and $10^{-7}$ dilutions. At $10^{-8}$ dilution, only $\mathrm{N}$ Charité had significantly higher Ct values (41.0 vs. 36.7 to 39.0 for N China CDC, N1 and N3 US CDC, and duplex RdRp IP2/IP4). 
Clinical samples $(n=4)$ were then tested using all RT-PCR assays to confirm the results obtained on SARS-CoV-2 cell culture supernatants (Supplementary Table S3). ORF1b and N HKU, ORF1ab and N China CDC, N1 and N3 US CDC, and RdRp IP2 and RdRp IP4 assays detected all four positive samples. S and NS RdRp, and N Charité assays did not detect the positive sample with the lowest viral concentration.

Taken together, N China CDC, N1 and N3 US CDC, as well as RdRp IP2 and IP4 were the most sensitive assays.

\subsection{Limit of Detection for the Most Sensitive Assays}

Due to a limited quantity of clinical sample available, only one target from each referral laboratory providing the most sensitive assays was tested: N China CDC, N1 US CDC, and RdRp IP2. The LoD of N3 US CDC was not determined as this assay is not specific for SARS-CoV-2 detection and was removed from the new version of the US CDC assay [13]. We chose to determine the LoD for RdRp IP2 and not IP4 as IP2 detected more replicates at the $10^{-9}$ dilution on cell culture supernatants.

The $95 \%$ hit rate obtained was $1.36 \log _{10} \mathrm{TCID}_{50} / \mathrm{mL}[0.8 ; 3.09]$ for $\mathrm{N}$ China CDC, $0.44 \log _{10} \mathrm{TCID}_{50} / \mathrm{mL}[0.05 ; 1.83]$ for N1 US CDC, and $0.63 \log _{10} \mathrm{TCID}_{50} / \mathrm{mL}[0.25 ; 1.9]$ for RdRp IP2. The differences observed were not statistically significant. For these three assays, the results were confirmed by additional testing of clinical samples (Figure 2, Supplementary Table S4). N1 US CDC and RdRp IP2 had lower Ct values than N China CDC (Figure 2), but no significant differences (Ct difference $<2$ ) were observed.

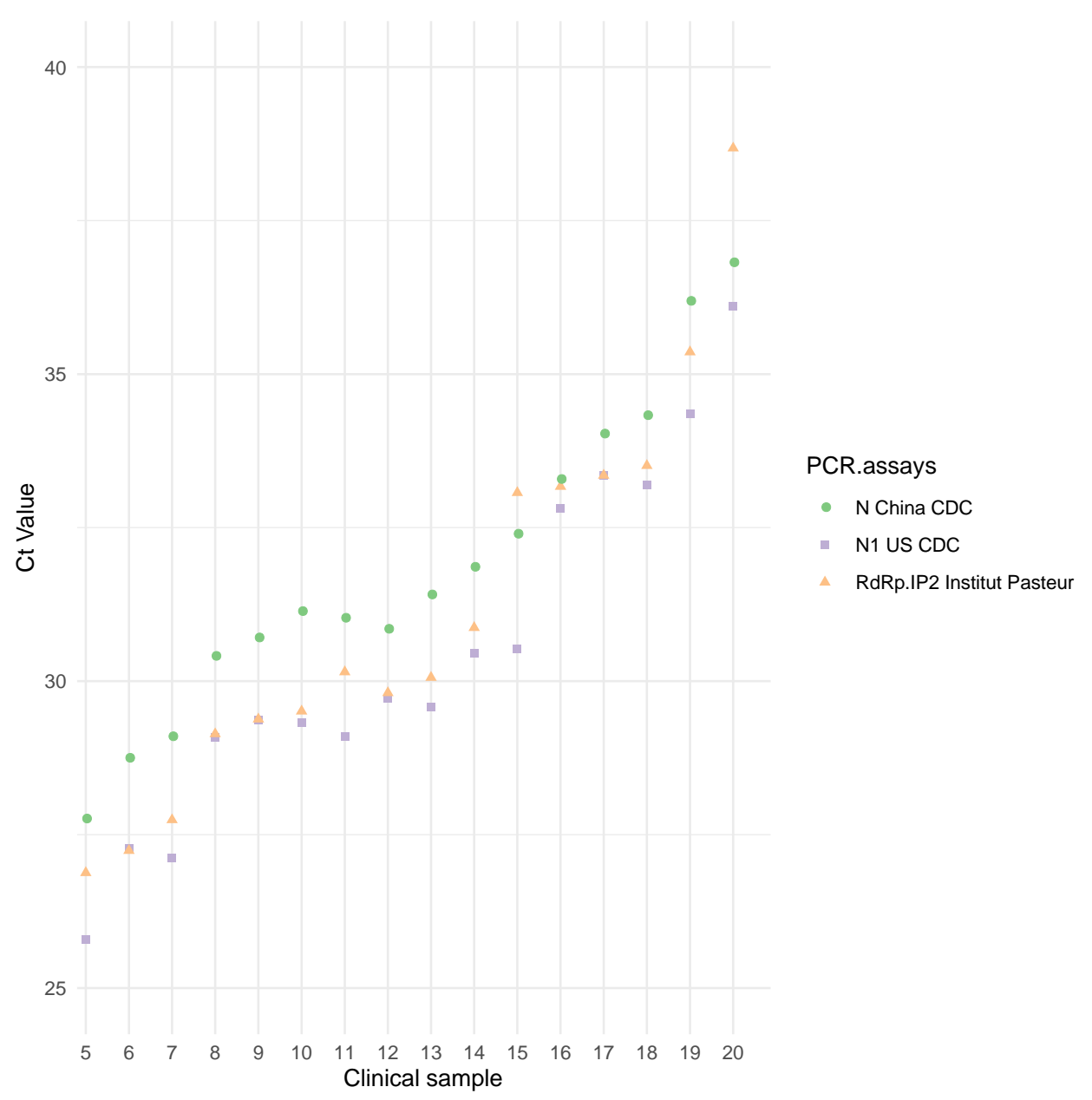

Figure 2. Ct values for 16 positive clinical samples using the three most sensitive assays. N China CDC is represented by green circles, N1 US CDC by purple squares, and RdRp IP2 Institut Pasteur, Paris, by orange triangles. 


\subsection{Specificity}

No false-positive results were obtained on clinical samples that tested negative for SARS-CoV-2 and/or positive for other viruses than SARS-CoV-2, except for E Charité and N2 US CDC, which were positive for all specimens (Supplementary Table S5).

\subsection{Exploration of E Charité and N2 US CDC False-Positive Results}

Since E Charité and N2 US CDC assays were positive for all specimens and replicates, including negative samples and controls, false-positive results were further explored (Supplementary Figure S1).

For E Charité, negative samples showed two amplicons, one at 84 base pairs (bp) and one at $121 \mathrm{bp}$, whereas the positive sample only had one amplicon at $121 \mathrm{bp}$, which is close to the expected size of a specific amplification (Table 1). Thus, the false-positive amplification obtained using E Charité might be derived from a contamination (amplicon size at $121 \mathrm{bp}$ ) but could also be associated with an aspecific amplification (amplicon size at $84 \mathrm{bp}$ ). Using the N2 US CDC assay, negative samples showed one amplicon at $73 \mathrm{bp}$, which is close to the expected size of a specific amplification (Table 1). Thus, the false-positive amplification obtained using N2 US CDC might be due to a contamination. Sequencing of these amplicon products should be performed for further investigation.

\section{Discussion}

The present study compared the performance of five RT-PCR-based methods developed by referral laboratories. N China CDC, N1 US CDC, and RdRp IP2 and IP4 were found to be the most sensitive assays on SARS-CoV-2 cell culture supernatants and clinical respiratory samples. Vogels et al. compared the performance of SARS-CoV-2 PCR assays developed by the same referral laboratories, except those from Institut Pasteur. Using RNA-spiked mock samples, they found that ORF HKU was one of the most sensitive assays [18]. Herein, ORF HKU was more sensitive than RdRp Charité but slightly less sensitive than other assays, such as N1 US CDC or N China. Although RdRp Charité performed well for the lowest dilutions, it was nevertheless found to be less sensitive than others, a result in line with those of Vogels et al. [18]. It is worth noting that the Charite assay was the first to be published at the early stage of the pandemic [9] and has been widely used worldwide [8]. This assay was initially designed for the diagnosis of SARS-related CoVs and then optimized for SARS-CoV-2 detection [5]. Thanks to this assay, an important number of COVID-19 diagnoses were made, which contributed to limiting the spread of the outbreak. In line with the present results, it was reported that RdRp IP2 and RdRp IP4 sensitivity was similar when used in multiplex [14], suggesting that the Institut Pasteur assay should preferentially be used in multiplex. Of note, we did not apply the Ct cut-off values above, in which a sample would be considered negative, since such values were not provided in the protocols made available by the referral laboratories.

As previously reported [19], we identified probable primer contamination using N2 US CDC and E Charité, which prevented us from further evaluating their sensitivity and specificity. Except for these two assays, no false-positive results were observed when testing a wide range of respiratory viruses, a result consistent with previous studies $[5,6,10,11,13,14]$. Although not observed herein, the amplification of non-specific products for ORF1 and N China CDC, and N2 and N3 US CDC has also been reported [18].

The performance of other RT-PCR tests recently developed [7] should be explored in further studies. In addition, the quantification of SARS-CoV-2 could be performed to assess the effectiveness of potential treatments. The data presented herein are of prime importance to facilitate the equipment choice of all diagnostic laboratories, as well as for the development of marketed tests. Sensitive tests should be widely implemented to limit the spread of the current outbreak and prepare for the post-epidemic phase and future seasonal epidemics. 
Supplementary Materials: The following are available online at http://www.mdpi.com/2077-0383/9/6/1871/s1. Figure S1: Electropherograms of amplicon sizes obtained using Agilent DNA 1000 kit (Agilent Technologies) for one positive sample and one negative sample for E Charité (Germany) and N2 US CDC (United States), respectively. Table S1: Cycle threshold values and mean \pm standard deviation for serial dilutions of SARS-CoV-2 cell culture supernatants obtained using IP2 and IP4 Institut Pasteur, Paris (France) when used in simplex and multiplex. Table S2: Cycle threshold values and mean \pm standard deviation for serial dilutions of SARS-CoV-2 cell culture supernatants obtained using five RT-PCR assays for SARS-CoV-2 detection made available by WHO, Table S3: Cycle thresholds values obtained on clinical samples $(n=4)$ using five RT-PCR assays for SARS-CoV-2 detection made available by WHO, Table S4: Cycle threshold values obtained on clinical samples $(n=16)$ using the three most sensitive methods: N China CDC, N1 US CDC, and IP2 Institut Pasteur, Paris (France). Table S5: Specificity assessment of five RT-PCR assays made available by WHO.

Author Contributions: Conceptualization, F.M. and A.G.; Methodology, S.E. and A.B.; Validation, S.E., A.B., and A.G.; Formal Analysis, S.E. and A.B.; Investigation, K.B.-P., V.C., and L.G.; Resources, S.E., A.B., K.B.-P., M.B., V.C., L.G., and A.G.; Data Curation, K.B.-P., V.C., and L.G.; Writing-Original Draft Preparation, S.E. and A.B.; Writing-Review and Editing, S.E., A.B., V.E., K.B.-P., M.B., G.D., G.B., L.J., E.F., F.M., and A.G.; Visualization, S.E., A.B., K.B.-P., G.O., and A.G.; Supervision, F.M. and A.G. All authors have read and agreed to the published version of the manuscript.

Funding: This research received no external funding. Reagents were provided by Laboratoire Commun de Recherche Hospices Civils de Lyon-bioMérieux, Centre Hospitalier Lyon Sud, Pierre-Bénite, France.

Acknowledgments: We would like to thank all the patients, clinicians, laboratory technicians, and informatics department who contributed to this investigation. We are also grateful to Véréna Landel and Philip Robinson (DRCI, Hospices Civils de Lyon) for help in the manuscript preparation. We also gratefully acknowledge the authors and laboratories that originated and submitted the sequence from GISAID's used to calculate amplicon sizes.

Conflicts of Interest: S.E., V.E., M.B., G.D., G.B., L.J., E.F., F.M., and A.G. declare no conflict of interest. A.B has received a research grant from bioMérieux. K.B.-P., V.C., L.G., and G.O. are employees at bioMérieux. The funders had no role in the design of the study; in the collection, analyses, or interpretation of data; in the writing of the manuscript, or in the decision to publish the results.

\section{References}

1. Coronaviridae Study Group of the International Committee on Taxonomy of Viruses The species Severe acute respiratory syndrome related coronavirus: Classifying 2019-nCoV and naming it SARS-CoV-2. Nat. Microbiol. 2020, 5, 536-544. [CrossRef] [PubMed]

2. World Health Organization WHO Announces COVID-19 Outbreak a Pandemic. Available online: http://www.euro.who.int/en/health-topics/health-emergencies/coronavirus-covid-19/news/news/2020/3/ who-announces-covid-19-outbreak-a-pandemic (accessed on 6 April 2020).

3. World Health Organization. Coronavirus Disease 2019 (COVID-19)—Situation Report-127. Available online: https://www.who.int/docs/default-source/coronaviruse/situation-reports/20200416-sitrep-87-covid19.pdf?sfvrsn=9523115a_2 (accessed on 26 May 2020).

4. Holmes, E.C. Novel 2019 Coronavirus Genome. Available online: http://virological.org/t/novel-2019coronavirus-genome/319 (accessed on 24 March 2020).

5. Corman, V.; Landt, O.; Kaiser, M.; Molenkamp, R.; Meijer, A.; Chu, D.; Bleicker, T.; Brünink, S.; Schneider, J.; Schmidt, M.L.; et al. Detection of 2019 novel coronavirus (2019-nCoV) by real-time RT-PCR. Eurosurveillance 2020, 25, 2000045. [CrossRef] [PubMed]

6. Corman, V.; Bleicker, T.; Brünink, S.; Drosten, C. Diagnostic Detection of 2019-nCoV by Real-Time RT-PCR; Charité Virology, Berlin, Germany. Available online: https:/www.who.int/docs/default-source/coronaviruse/ protocol-v2-1.pdf?sfvrsn=a9ef618c_2 (accessed on 24 March 2020).

7. Cormac, S. Coronavirus and the Race to Distribute Reliable Diagnostics. Available online: https://www. nature.com/articles/d41587-020-00002-2 (accessed on 24 March 2020).

8. Reusken, C.; Broberg, E.; Haagmans, B.; Meijer, A.; Corman, V.; Papa, A.; Charrel, R.; Drosten, C.; Koopmans, M.; Leitmeyer, K.; et al. Laboratory readiness and response for novel coronavirus (2019-nCoV) in expert laboratories in 30 EU/EEA countries, January 2020. Eurosurveillance 2020, 25, 2000082. [CrossRef] [PubMed]

9. World Health Organization. Coronavirus Disease (COVID-19) Technical Guidance: Laboratory Testing for 2019-nCoV in Humans. Available online: https:/www.who.int/emergencies/diseases/novel-coronavirus2019/technical-guidance/laboratory-guidance (accessed on 30 March 2020). 
10. Chu, D.; Pan, Y.; Cheng, S.; Hui, K.; Krishnan, P.; Liu, Y.; Ng, D.; Wan, C.; Yang, P.; Wang, Q.; et al. Molecular diagnosis of a novel Coronavirus (2019-nCoV) causing an outbreak of pneumonia. Clin. Chem. 2020, 66, 1-7. [CrossRef] [PubMed]

11. HKU Med. Detection of 2019 Novel Coronavirus (2019-nCoV) in Suspected Human Cases by RT-PCR. Available online: https:/www.who.int/docs/default-source/coronaviruse/peiris-protocol-16-120.pdf?sfvrsn=af1aac73_4 (accessed on 24 March 2020).

12. China CDC. China CDC Primers and Probes for Detection 2019-nCoV. Available online: http://ivdc.chinacdc. cn/kyjz/202001/t20200121_211337.html (accessed on 24 March 2020).

13. Centers for Disease Control and Prevention. A CDC 2019-Novel Coronavirus (2019-nCoV) Real-Time RT-PCR Diagnostic Panel. Available online: https://www.fda.gov/media/134922/download (accessed on 24 March 2020).

14. Institut Pasteur, Paris. Protocol: Real-Time RT-PCR Assays for the Detection of SARS-CoV-2. Available online: https://www.who.int/docs/default-source/coronaviruse/real-time-rt-pcr-assays-for-the-detectionof-sars-cov-2-institut-pasteur-paris.pdf?sfvrsn=3662fcb6_2 (accessed on 24 March 2020).

15. Barron, A.; Olshevsky, C.; Cohen, M. Characteristics of the BGM line of cells from African green monkey kidney. Brief report. Arch. Gesamte Virusforsch. 1970, 32, 389-392. [CrossRef] [PubMed]

16. Reed, L.; Muench, H. A Simple Method of Estimating Fifty Per Cent Endpoints. Am. J. Epidemiol. 1938, 27, 493-497. [CrossRef]

17. Baraduc, M.; Baume, A.; Bouvet, F.; Canis, C.; Cattoen, S.; Charachon, V.; Cocquerelle, R.; Courcol, C.; de Champs, M.; Ferroni, N.; et al. SFM comparaison de methodes. In Comite Qualite (QUAMIC) de la Société Francaise de Microbiologie—Recommandations 2014; Société Francaise de Microbiologie: Paris, France, 2014; p. 146.

18. Vogels, C.; Brito, A.; Wyllie, A.; Fauver, J.; Ott, I.; Kalinich, C.; Petrone, M.; Landry, M.; Foxman, E.; Grubaugh, N. Analytical sensitivity and efficiency comparisons of SARS-COV-2 qRT-PCR assays (Preprint). Prepr. MedRxiv. Available online: https://www.medrxiv.org/content/10.1101/2020.03.30.20048108v1.full.pdf (accessed on 2 April 2020).

19. Mögling, R.; Meijer, A.; Berginc, N.; Bruisten, S.; Charrel, R.; Coutard, B.; Eckerle, I.; Enouf, V.; Hungnes, O.; Korukluoglu, G.; et al. Early release-Delayed laboratory response to COVID-19 caused by molecular diagnostic contamination. Emerg. Infect. Dis. J. CDC. 2020, 26, 1843. [CrossRef] 